Discussion on a paper published in the

Magazine of Concrete Research

Volume 33, Number 117 : December 1981

\title{
Effect of in-source variability of pulverized-fuel ash upon the strength of OPC/pfa concrete*
}

\author{
Ravindra K. Dhir, Arun G. Apte and John G. L. Munday \\ Contribution by J. van Dijk \\ National Building Research Institute, CSIR, Pretoria, South Africa
}

The variability of pfa and its infiuence upon the concrete-making properties of the material are also causing concern in South Africa and therefore I would like to congratulate the authors on their interesting and stimulating paper and for their effort to clarify certain misconceptions.

The authors used Smith's method of cementing efficiency factors to design their OPC/pfa concrete mixes. When I use this method to design OPC/pfa mixes, which are the most economical from the point of view of the cost of the concreting materials and which have the same workability and compressive strength as the OPC concretes, I invariably find that the $\mathrm{F} / \mathrm{C}$ ratios are far too high and that the mixes become too sticky. From the basic mix proportions, given in the paper in Table 2 on page 200 , the $F / C$ ratios, especially for the mixes M1 and M3, seem very high. These high values would only be practical when the coarse to fine aggregate ratios of the OPC/pfa mixes were increased considerably in comparison with those of the OPC mixes or when working with a very coarse sand. I have calculated that the fineness modulus of the sand used in the investigation was $3 \cdot 14$, which is rather high and would have resulted, most probably, in rather harsh OPC concretes, especially in the case of the leaner mixes. It would be

*Pages 199 to 207 of $M C R 117$. appreciated if the authors could give more information on the placeability, stickiness and harshness of the OPC/pfa mixes in comparison with the OPC mixes. It should be mentioned here that, for the purpose of the paper, to investigate the effect upon the strength of OPC/pfa concrete of the variability of pulverized-fuel ashes, the selection of high $\mathrm{F} / \mathrm{C}$ values was justified.

The aggregate/cement ratios were apparently not determined by using Smith's formulae. If this assumption is correct, could the authors explain how they arrived at the aggregate/cement ratios?

The differences in the OPC contents of the OPC concretes and the OPC/pfa concretes were calculated by using the averages for the mixes M1, M3 and M5 in Table 2 of the paper. F1 of mix M1 was excluded because of its high cement content compared to the cement contents of F2, F3 and F4 of mix M1. The differences in OPC contents, when expressed as a percentage of the comparable OPC concretes, show a linear relationship with the compressive strengths at 28 days of the OPC/pfa concretes. When the average pfa contents of the three mixes M1, M3 and M5 are compared with their compressive strengths, a linear relationship is also evident. The work done at NBRI on a pfa, with a good cementing efficiency factor $(0.48$ at a compressive strength of $35 \mathrm{~N} / \mathrm{mm}^{2}$ ), also showed linear relationships, although not the same as those 
obtained using the results in the paper. The differences in the relationships are probably due to the differences in $\mathrm{F} / \mathrm{C}$ contents of the mixes used by the authors and at NBRI. If, however, with the same workability, stickiness and types of aggregates, the same linear relationships are found, the design of $\mathrm{OPC} / \mathrm{pfa}$ concretes would be simple.

It is mentioned in the paper, on page 200 , that the variation in water demand of different samples of pfa was accommodated by adjusting the aggregate contents at the mixer to maintain constant design workability. This can easily be done in a laboratory and it also ensures a lower variation in strength than when the workability is adjusted by changing the water content of a mix. On a building site, however,

\section{Reply by the authors}

We are grateful to $\mathrm{Mr}$ van Dijk for his comments which we shall try to answer in the order in which he has presented them.

We would agree with his observation that, at the lower end of the strength range, Smith's method of mix design does result in concretes having a high ash content. If the ash and cement proportions of the mixes we used are expressed in terms of an ash to total cementitious ratio, $F /(F+C)$, however, only that for the mix M1 $(0.60$ approximately) exceeds the frequently suggested ${ }^{(1-5)}$ limit of $F /(F+C)=0.5$; the other mixes are both well within this limit (M3:0.40 and M5:0.15 approximately). Mr van Dijk is correct in his calculation of the fineness molulus of the sand used and also in his assessment of the effect of this on the leanest mix. The OPC concrete of mix M1 was somewhat on the harsh side, but the addition of pfa to this mix produced a perfectly satisfactory concrete, the high ash content eliminating the harshness without causing stickiness. Mixes M3 and M5 were all quite acceptable, the OPC and OPC/pfa mixes being neither harsh nor sticky, and there was no necessity to alter the fine aggregate proportions (which varied from $47 \%$ to $37 \%$ of the total aggregate content for mixes M1 to M5 respectively) for the OPC/pfa concrete in any way.

We can confirm that, for the $\mathrm{OPC} / \mathrm{pfa}$ concretes, the aggregate/cement ratios were calculated by Smith's method, using values of $(\mathrm{W} / \mathrm{C})_{\mathrm{w}}^{\prime}=0.375$ and $N=3.34$ in the appropriate equations. As explained on page 200 , the basic mix proportions given in Table 2 of the paper were obtained with $k$ values determined on the basis of trial mixes. These trials were carried out using the first samples of each ash and the proportions shown in Table 2 were subject to some variation for subsequent samples in order to maintain workability in the target range of $30-60 \mathrm{~mm}$ slump. A summary of the variations in cement content and the aggregate content of a mix is usually a fixed mass and the mixer operator will adjust the water content more readily than the aggregate content, for obvious practical reasons. This may result in larger variations than those found in the laboratory results. To judge the influence of the water demands of the different ashes, perhaps the authors could give the final mix proportions of the mixes which were tested?

On pages 204 and 205 of the paper, it is mentioned that the strength variation exhibited in curing condition E4 tended to be somewhat higher than in the other curing conditions. Most concretes, especially in 'low humidity' countries, cure under condition E4 and it would be of interest to know the extent of the variations under condition $\mathrm{E} 4$.

aggregate/cement ratio produced by the adjustment of aggregate content is given in Table $\mathrm{I}$ (the $\mathrm{W} / \mathrm{C}$ and $\mathrm{F} / \mathrm{C}$ ratios remained constant at the values given in Table 2). It is apparent from Table I that, whilst quite large adjustments were required for the ash F1, ash $F 2$, which had an equally large variation in water demand (as measured by standard consistence, Table 4) from sample to sample, did not require nearly as great a range of adjustments in aggregate content. This again must call into question the suitability of these standard test procedures and their value as predictive tools. With ashes F3 and F4 the workability for different samples remained within the required range with little or no adjustments to the mix proportions and thus no difference in the strength variation should be expected from these ashes for the different methods of accommodating the different water demands of ash samples.

We were interested to note Mr van Dijk's analysis of our data in terms of the relationships between average cement reductions, average ash contents and average compressive strengths. We have not explored these relationships since, although we agree with $\mathrm{Mr}$ van Dijk that the mix design of OPC/pfa concretes could be simplified, we believe that there are alternative methods ${ }^{(6,7)}$ which can give the desired degree of simplification while at the same time taking account of individual rather than average ash characteristics.

Finally, we regret that it was possible to present only a selection of our data in the paper. We hope that Table II provides sufficient information on the extent of strength variation of both OPC and OPC/pfa concretes under conditions of low relative humidity. Comparison of Table II with Table 7 from the paper shows that, as stated, in almost all cases the strength variability, as measured by the coefficient of variation, was greater for curing conditions E4 and E2. 
TABLE I: Variation in mix cement content and aggregate/ cement ratios as a result of maintaining constant workability by adjusting aggregate content at mixer.

\begin{tabular}{|c|c|c|c|c|c|c|c|}
\hline \multirow[b]{2}{*}{ Mix } & \multirow{2}{*}{$\begin{array}{c}\text { Source } \\
\text { of } \\
\text { pfa }\end{array}$} & \multicolumn{3}{|c|}{$\begin{array}{l}\text { Cement content } \\
\qquad\left(\mathrm{kg} / \mathrm{m}^{3}\right)\end{array}$} & \multicolumn{3}{|c|}{ Aggregate/cement ratio } \\
\hline & & Range & Mean & $\begin{array}{l}\text { Standard } \\
\text { deviation }\end{array}$ & Range & Mean & $\begin{array}{l}\text { Standard } \\
\text { deviation }\end{array}$ \\
\hline \multirow{4}{*}{ M1 } & F1 & $134-206^{*}$ & 152 & $17 \cdot 3$ & $6 \cdot 83-13 \cdot 77$ & $11 \cdot 53$ & $1 \cdot 75$ \\
\hline & F2 & $130-138$ & 132 & $2 \cdot 2$ & $12 \cdot 96-14 \cdot 08$ & $13 \cdot 75$ & $0 \cdot 31$ \\
\hline & F3 & $119-121$ & 119 & $0 \cdot 6$ & $15 \cdot 47-15 \cdot 82$ & $15 \cdot 79$ & $0 \cdot 11$ \\
\hline & F4 & $119-210$ & 119 & $0 \cdot 5$ & $15 \cdot 77-16 \cdot 00$ & $15 \cdot 93$ & $0 \cdot 11$ \\
\hline \multirow{4}{*}{ M3 } & F1 & $210-295^{*}$ & 235 & $20 \cdot 8$ & $5 \cdot 25-8 \cdot 89$ & $7 \cdot 60$ & 0.93 \\
\hline & $F 2$ & $216-235$ & 226 & $4 \cdot 2$ & $7 \cdot 59-8 \cdot 58$ & $8 \cdot 04$ & $0 \cdot 22$ \\
\hline & F3 & $205-208$ & 205 & 0.9 & $8 \cdot 87-9 \cdot 01$ & $9 \cdot 00$ & 0.04 \\
\hline & F4 & $213-216$ & 213 & $0 \cdot 7$ & $8 \cdot 72-8 \cdot 58$ & $8 \cdot 71$ & 0.03 \\
\hline \multirow{4}{*}{ M5 } & F1 & $349-433^{*}$ & 384 & $20 \cdot 3$ & $3 \cdot 78-5 \cdot 26$ & $4 \cdot 60$ & $0 \cdot 36$ \\
\hline & $\mathbf{F} 2$ & $369-380$ & 374 & $4 \cdot 7$ & $4 \cdot 62-4 \cdot 84$ & $4 \cdot 75$ & $0 \cdot 09$ \\
\hline & F3 & 359 & 359 & 0 & 4.98 & 4.98 & 0 \\
\hline & F4 & $364-371$ & 364 & $1 \cdot 7$ & $4.77-4.94$ & $4 \cdot 89$ & $0 \cdot 03$ \\
\hline
\end{tabular}

${ }^{*}$ Next highest value for mix $M 1$ is $176 \mathrm{~kg} / \mathrm{m}^{3}$, giving a corresponding $\mathrm{A} / \mathrm{C}$ ratio of 9.00 , for $\mathrm{M} 3,263 \mathrm{~kg} / \mathrm{m}^{3}$ with $\mathrm{A} / \mathrm{C}$ ratio of 6.33 and for $\mathrm{M} 5,405 \mathrm{~kg} / \mathrm{m}^{3}$ with $\mathrm{A} / \mathrm{C}$ ratio of $4 \cdot 20$; all for the same pfa sample No.

T A B LE I I: Strength variability of $\mathrm{OPC} / \mathrm{pfa}$ and $\mathrm{OPC}$ concretes for curing conditions $\mathrm{EA}$ (air at $20^{\circ} \mathrm{C}, 50-60 \% \mathrm{RH}$ ).

\begin{tabular}{l|c|c|c|c|c|c}
\hline \multirow{2}{*}{ Mix } & \multicolumn{4}{|c}{$\begin{array}{c}\text { 28 day cube strength } \\
\left(\mathrm{N} / \mathrm{nm}^{2}\right)\end{array}$} \\
\cline { 3 - 7 } & $\begin{array}{c}\text { Source } \\
\text { of } \\
\text { pfa }\end{array}$ & $\begin{array}{c}\text { First } \\
\text { sample } \\
\text { value }\end{array}$ & $\begin{array}{c}\text { Sample } \\
\text { range }\end{array}$ & Mean & $\begin{array}{c}\text { Standard } \\
\text { deviation }\end{array}$ & $\begin{array}{c}\text { Coefficient } \\
\text { of variation } \\
(\%)\end{array}$ \\
\hline
\end{tabular}

(a) OPC/PFA CONCRETES USING 20 WEEKLY PFA SAMPLES WITH BULK CEMENT

\begin{tabular}{|c|c|c|c|c|c|c|}
\hline M1 & $\begin{array}{l}\text { F1 } \\
\text { F2 } \\
\text { F3 } \\
\text { F4 }\end{array}$ & $\begin{array}{l}11 \cdot 0 \\
12 \cdot 5 \\
11 \cdot 9 \\
12 \cdot 0\end{array}$ & $\begin{array}{l}10 \cdot 2-14 \cdot 9 \\
11 \cdot 1-13 \cdot 8 \\
10 \cdot 1-12 \cdot 5 \\
10 \cdot 4-15 \cdot 0\end{array}$ & $\begin{array}{l}12 \cdot 5 \\
12 \cdot 3 \\
11 \cdot 5 \\
12 \cdot 1\end{array}$ & $\begin{array}{l}1.5 \\
0.8 \\
0.7 \\
1.0\end{array}$ & $\begin{array}{r}11 \cdot 6 \\
6 \cdot 1 \\
5 \cdot 7 \\
8 \cdot 2\end{array}$ \\
\hline M3 & $\begin{array}{l}\text { F1 } \\
\text { F2 } \\
\text { F3 } \\
\text { F4 }\end{array}$ & $\begin{array}{l}24 \cdot 7 \\
24 \cdot 7 \\
24 \cdot 0 \\
25 \cdot 7\end{array}$ & $\begin{array}{l}22 \cdot 8-29 \cdot 0 \\
24 \cdot 7-28 \cdot 4 \\
21 \cdot 5-24 \cdot 9 \\
24 \cdot 4-28 \cdot 9\end{array}$ & $\begin{array}{l}25 \cdot 2 \\
26 \cdot 5 \\
23 \cdot 5 \\
25 \cdot 9\end{array}$ & $\begin{array}{l}1 \cdot 5 \\
1 \cdot 0 \\
0 \cdot 9 \\
1 \cdot 3\end{array}$ & $\begin{array}{l}6 \cdot 1 \\
3 \cdot 8 \\
3 \cdot 8 \\
4 \cdot 9\end{array}$ \\
\hline M5 & $\begin{array}{l}F 1 \\
F 2 \\
F 3 \\
F 4\end{array}$ & $\begin{array}{l}47 \cdot 2 \\
46 \cdot 7 \\
44 \cdot 7 \\
42 \cdot 5\end{array}$ & $\begin{array}{l}44 \cdot 0-50 \cdot 8 \\
42 \cdot 6-48 \cdot 6 \\
38 \cdot 5-45 \cdot 3 \\
41 \cdot 5-49 \cdot 6\end{array}$ & $\begin{array}{l}46 \cdot 6 \\
46 \cdot 2 \\
42 \cdot 8 \\
44 \cdot 3\end{array}$ & $\begin{array}{l}1.8 \\
1.7 \\
1.7 \\
1.6\end{array}$ & $\begin{array}{l}3 \cdot 8 \\
3 \cdot 6 \\
4 \cdot 0 \\
3 \cdot 6\end{array}$ \\
\hline
\end{tabular}

(b) OPC/PFA CONCRETES USING 20 WEEKLY Y CEMENT SAMPLES WITH BULK PFA

\begin{tabular}{l|c|c|c|c|c|c}
\hline & OPC & $27 \cdot 8$ & $23 \cdot 0-28 \cdot 7$ & $25 \cdot 6$ & $1 \cdot 4$ & $5 \cdot 6$ \\
M3 & F1 & $24 \cdot 1$ & $23 \cdot 0-28 \cdot 0$ & $25 \cdot 2$ & $1 \cdot 4$ & $5 \cdot 7$ \\
& F2 & $26 \cdot 3$ & $23 \cdot 2-27 \cdot 8$ & $25 \cdot 9$ & $1 \cdot 3$ & $5 \cdot 0$ \\
\hline
\end{tabular}




\section{REFERENCES}

1. Cannon, R. W. Proportioning fly ash concrete mixes for strength and economy. Journal of the American Concrete Institute. Proceedings Vol. 65, No. 11. November 1968. pp. 969-979.

2. GHOSH, R. S. Proportioning concrete mixes incorporating fly ash. Canadian Journal of Civil Engineering. Vol. 3, 1976. pp. 68-82.

3. ROSNER, J. c. Lets design fly ash concretes: not compare them. Proceedings, Fourth International Ash Utilization Symposium (St Louis, March 1976). Washington, D.C., U.S. Bureau of Mines, 1976. pp. 560-572. ERDA MERC/SP-76/4.

4. owens, P. L. Pulverized-fuel ash - Part 2. Concrete, Vol. 13, No. 10. October 1980. pp. 33-34. Current Practice Sheet 57.
5. новвs, D, w. The effects of pulverized-fuel ash upon the workability of cement paste and concrete. Magazine of Concrete Research. Vol. 32, No. 113. December 1980. pp. 219-226.

6. ONG, L. T., MUNDAY, J. G. L. and DhiR, R. K. Mix design of $\mathrm{OPC} / \mathrm{pfa}$ concrete. Proceedings, International symposium on the use of pfa in concrete (Leeds, U.K., April 1982). Vol. 1. pp. 173-180.

7. MUNDAY, J. G. L., ONG, L. T. and DHIR, R. K. Mix proportioning of concrete with PFA-a critical review. Paper to be presented at First International Conference on the use of Fly Ash, Silica Fume, Slag and Other Mineral By-Products in Concrete, Ottawa, 31 July-5 August 1983. 